\title{
Исследование структуры объемного гетероперехода в полимерных солнечных элементах с помощью комбинации ультрамикротомирования и атомно-силовой микроскопии
}

\author{
(C) А.М. Алексеев ${ }^{1,2}$, А. Ал-Афреефо ${ }^{3}$, Г.Д. Хедли ${ }^{4}$, С.С. Харинцев ${ }^{5}$, \\ A.E. Ефимов ${ }^{6}$, А.Т. Едрисов ${ }^{1}$, Н.А. Дюжев ${ }^{2}$, И.Д.В. Самуэль ${ }^{4}$ \\ 1 „Национальная лаборатория Астана“, Назарбаев Университет, \\ 010000 Астана, Казахстан \\ ${ }^{2}$ Национальный исследовательский университет „Московский институт электронной техники“, \\ 124498 Москва, Россия \\ ${ }^{3}$ Университет г. Глазго, \\ G12 8QQ Глазго, Великобритания \\ ${ }^{4}$ Университет г. Сент-Эндрюс, \\ KY16 9AJ Шотландия, Великобритания \\ ${ }^{5}$ Институт фризики, Казанский федеральный университет, \\ 420111 Казань, Россия \\ ${ }^{6}$ Федеральный научный центр трансплантологии и искусственных органов им. академика В.И. Шумакова, \\ 123182 Москва, Россия \\ E-mail: alalrus@gmail.com
}

(Получена 9 февраля 2017 г. Принята к печати 21 февраля 2017 г.)

\begin{abstract}
В работе описан и применен способ визуализации внутренней структуры фотоактивных слоев полимерных солнечных батарей методами атомно-силовой микроскопии, основанный на использовании ультрамикротома для получения срезов фотоактивного слоя. Данный метод позволяет использовать преимущества атомно-силовой микроскопии при изучении структуры в объеме мягких образцов, такие как высокий контраст изображений и способность измерять различные свойства поверхности с нанометровым разрешением. Описанным методом исследованы образцы фотоактивного слоя полимерного солнечного элемента на основе смеси производной тиофена РТВ7 и производной фуллерена $\mathrm{PC}_{71} \mathrm{BM}$. Обнаружены новые детали внутренней структуры данной смеси, позволяющие сделать дополнительные выводы о влиянии морфологии на эффективность органических солнечных элементов.
\end{abstract}

DOI: 10.21883/FTP.2018.01.45328.8545

\section{1. Введение}

В последние годы в лабораториях и компаниях разрабатываются и активно изучаются солнечные элементы на основе органических материалов. Одним из наиболее перспективных направлений является разработка полимерных солнечных батарей, эффективность преобразования энергии которых превысила 10\% [1-3]. С учтом простоты и дешевизны производства таких батарей достигнутые значения эффективности делают их использование экономически целесообразным. Дальнейшее увеличение эффективности полимерных солнечных элементов (ПСЭ) требует детального знания морфологии фотоактивного слоя, который в современных образцах ПСЭ представляет собой смесь органических донора и акцептора, формирующих объемный гетеропереход [4]. Структура объемного гетероперехода определяет ряд важнейших процессов в ПСЭ, таких как диффузия экситонов, их диссоциация и транспорт заряда к электродам.

Среди различных методов изучения наноструктуры фотоактивных слоев одними из наиболее широко применяемых методов являются атомно-силовая микроскопия (ACM) и просвечивающая электронная микроскопия (ПЭМ) [5-9]. Два данных метода дают комплементарную информацию о наноструктуре образца, так как АСМ является методом для изучения поверхности и ПЭМ дает информацию о проекции объемной структуры. Обычно для исследования структуры фотоактивного слоя методом АСМ пленка наносится центрифугированием на стекло, покрытое оксидом индия-олова. При этом верхний электрод и транспортные слои не наносятся и зонд АСМ имеет доступ к поверхности фотоактивной пленки. Для измерений ПЭМ фотоактивный слой с такого образца переносится на стандартную решетку для ПЭМ-измерений. Крайне важной задачей является получение информации о структуре пленки в плоскости, перпендикулярной поверхности, т. е. между электродами. Такая задача является технически сложной и требует применения различных методов модификации поверхности с нанометровым пространственным разрешением. Для получения образцов с сечением фотоактивного слоя используются, как правило, либо микротомирование, либо вырезание ламели фокусированым ионным пучком (ФИП) [10]. Полученные образцы сечений ПСЭ в основном исследовались методами ПЭМ, обеспечивающими высокое пространственное разрешение (как правило, лучше 1 нм) и возможность химического анализа (например, энергетически фильтруемая просвечивающая электронная микроскопия, ЭФПЭМ) [11]. Также распространено исследование сечения образца, полученного сколом 
в жидком азоте, методами сканирующей электронной микроскопии, которая, как правило, не позволяет достигнуть необходимого разрешения. Результаты, полученные ПЭМ на органических образцах, отличаются плохим контрастом из-за низкого атомного номера элементов, входящих в состав материалов, помимо этого происходит быстрое разрушение образцов под действием электронного луча. В отличие от ПЭМ, сканирующая зондовая микроскопия (С3М) позволяет проводить измерения органических образцов практически без разрушения. Кроме того, использование различных режимов АСМ обеспечивает получение хорошего контраста на гетерогенных органических образцах тем или иным способом. Таким образом, комбинируя микротомирование с АCM, можно получать детальную информацию о структуре органических образцов в объеме, измеряя различные типы взаимодействия зонда АСМ с образцом, содержащим сечение фотоактивного слоя. В недавней работе [12] комбинация ультрамикротомирования и АСМ была использована для измерения распределения потенциала по сечению ПСЭ. В данной работе мы используем подобный подход, но с применением других, более высокоразрешающих методов АСМ и для более актуальных материалов. Нами исследовались образцы фотоактивной пленки на основе производной политиофена с общепринятой аббревиатурой PTB7, Poly(\{4,8-bis[(2-ethylhexyl)oxy]benzo [1,2-b : 4,5-b' $]$ dithiophene-2,6-diyl $\}\{3$-fluoro-2- [ (2-ethylhexyl) carbonyl] thieno[3,4-b] thiophenediyl $\})$, и акцептора на основе фуллерена $\mathrm{PC}_{71} \mathrm{BM},[6,6]$-phenyl-C71butyric acid methyl ester [13]. Именно для этой смеси c добавкой 3\% дииодоктана (ДИО) было получено рекордное значение эффективности преобразования энергии однослойного ПСЭ, равное 9.2\% [14]. Данная смесь активно изучалась различными методами, и в целом структура данного фотоактивного слоя достаточно хорошо изучена [15-19]. Однако остался ряд открытых вопросов, касающихся именно объемной конфигурации гетероперехода между электродами. Целью данной работы является получение данных о наноструктуре фотоактивных слоев на основе полимера РТВ7 в объеме. Для этого полученные ультрамикротомированием сечения фотоактивных слоев исследовались методами АСМ. В качестве комплементарного метода нами была использована сканирующая просвечивающая электронная микроскопия с применением высокоуглового кольцевого темнопольного детектора (ВКТД-СПЭМ). В ряде работ было показано, что применение данного метода на органических композитах позволяет заметно улучшить контраст при использовании ПЭМ [11,20,21]. Сравнение данных, полученных комбинацией ультрамикротома и АСМ, с результатами ФИП-ПЭМ показывает отсутствие значительных повреждений и деформаций фотактивного слоя при микротомировании, а также хорошую корреляцию результатов, полученных двумя методами. В то же время ПЭМ не в состоянии обнаружить некоторые детали структуры, четко видимые на СЗМ-изображениях. Актуальность полученных результатов подтверждается недавними работами, в которых использовалась моди- фикация РТВ7, позволяющая достигать еще бо́льших значений эффективности преобразования энергии $[3,22]$.

\section{2. Материалы и методы}

При изготовлении образцов для микротомирования использовались подложки полиэтилентерефталата (ПЭТ), на которые стандартными методами центрифугирования наносились дырочный транспортный слой poly(3,4-ethylenedioxythiophene) poly(styrenesulfonate) (PEDOT:PSS) (Clevios AI4083) и фотоактивный слой РТВ7: $\mathrm{PC}_{71} \mathrm{BM}$. Раствор РТВ7: $\mathrm{PC}_{71} \mathrm{BM}$ в хлорбензоле был приготовлен в концентрации 25 мг/мл при массовом соотношении $1: 1.5$. Перед центрифугированием раствор перемешивался в течение 5 ч при температуре $50^{\circ} \mathrm{C}$. Смесь наносилась в перчаточном боксе в атмосфере азота при скорости вращения 1000 об/мин в течение 1 мин. При использовании раствора с 3 об\% дииодоктана образцы после нанесения пленки помещались в вакуум (остаточное давление $10^{-5}$ мбар) для удаления остатков ДИО. Сверху полученный образец покрывался аморфным фторполимером CYTOP (AGC Chemicals Europe) толщиной несколько микрометров. Таким образом получался образец, содержащий фотоактивный слой, пригодный для получения сечения методом микротомирования. Непосредственно перед микротомированием образец также был залит эпоксидной смолой, и с помощью стеклянного ножа предварительно была сформирована пирамидальная заготовка. При микротомировании в нормальных условиях толщина срезов была 200 нм. Отрезание слоев образца проводилось с помощью ультрамикротома Leica UC6 в нормальных условиях. Сечения образца, плавающие на поверхности кюветы ножа после срезания, наносились на тонкое (толщиной 0.17 мм) предметное стекло (рис. 1, $a$ ). Таким образом получались образцы, пригодные для исследования структуры гетероперехода в объеме методами оптической и зондовой микроскопии. Толщина среза $d$ проверялась путем измерения топографии поверхности вблизи края среза (рис. $1, b)$. Из рис. $1, b$ видно, что толщина $d$ хорошо согласуется с установками в программе микротома, хотя и есть некоторое отклонение в меньшую сторону, что может объясняться параметрами микротомирования и механическими свойствами образца. В целом поверхность срезов является гладкой (шероховатость поверхности много меньше толщины среза). Выраженные темные линии на рис. 1, $a$ являются складками, возникшими при переносе среза на стеклянную подложку. При сканировании поверхности АСМ выбирались области между складками.

Были изготовлены образцы двух типов: с фотоактивными слоями РТВ7:PC 71 ВМ и РТВ7:PC 71 ВM с добавкой 3\% ДИО (в дальнейшем обозначаемого как PTB7:PC 71 BM:DIO). При нанесении фотоактивного слоя на подложку ПЭТ использовался тонкий промежуточный центрифугированный подслой PEDOT:PSS для сохранения структуры фотоактивного слоя такой же, 


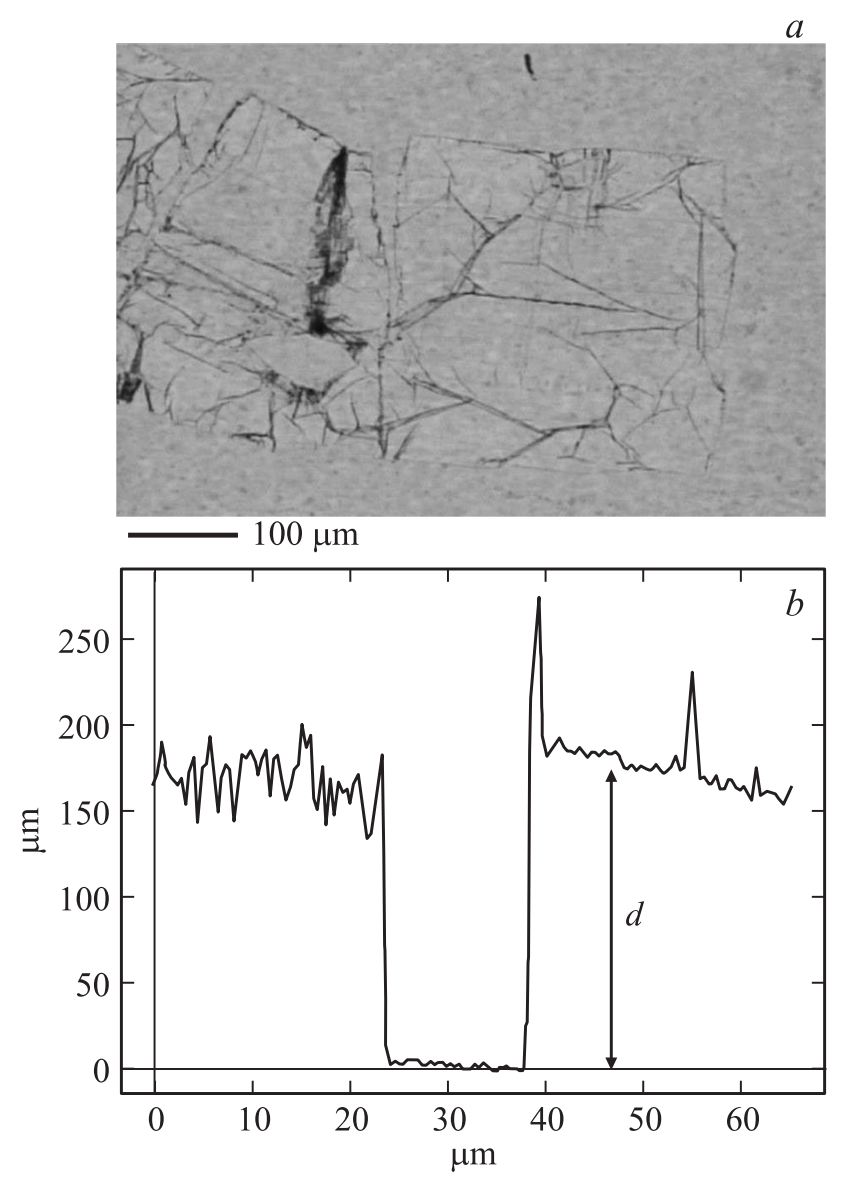

Рис. 1. Оптическое изображение среза образца на стекле $(a)$ и профиль среза на стекле, измеренный методом АCM $(b)$.

как в стандартных образцах с подложкой стекло//оксид индия-олова $\rangle$.

Для исследований ПЭМ фотоактивные слои наносились на стандартную подложку стекло//оксид индия-олова $\rangle$, покрытую центрифугированным слоем PEDOT: PSS, как описано в [11]. Толщина пленки с ДИО, нанесенной на ПЭТ, была больше, чем при использовании стандартной подложки с оксидом индия-олова.

СЗМ-измерения проводились на установке Интегра Аура (НТ-МДТ) с помощью зондов NSG01 и CSG10 (НТ-МДТ). Фазовый контраст измерялся в полуконтактном режиме, при котором доминируют силы отталкивания.

Для приготовления ламели с сечением фотоактивного слоя для исследования методом ПЭМ использовалась двулучевая система NovaNanolab 100, комбинирующая сканирующий электронный микроскоп и фокусированный ионный пучок (FEI). Ламель с размерами 10 мкм $\times 4$ мкм $\times 80$ нм вырезалась перпендикулярно поверхности образца и содержала все имеющиеся слои. Измерения ПЭМ проводились на микроскопе ARM (JEOL).

Измерения спектров гигантского комбинационного рассеяния света (ГКР), усиленного плазмонной нано- антенной, проводились на установке ИНТЕГРА СПЕКТРА (НТ-МДТ). Для этой цели была использована инвертированная оптическая схема и СЗМ-конфигурация с измерением боковых сил, использующая кварцевый резонатор с приклеенной золотой наноантенной. Оптическая наноантенна конусной формы была получена с помощью адаптивного электрохимического травления золотой проволоки в растворе соляной кислоты $(37 \%)$ и этилового спирта (96\%) в объемной пропорции $1: 1[23,24]$. Для измерений использовался лазер с длиной волны 532 нм.

\section{3. Результаты и обсуждение}

Приготовленные образцы, содержащие сечения фотоактивных слоев PTB7:PC 71 ВM и PTB7:PC 71 BM:DIO, нанесенные на стеклянную подложку, исследовались методами зондовой микроскопии с целью выявления структуры фотоактивного слоя в объеме. Ранее структура таких пленок исследовалась зондовой и электронной микроскопией, а также рентгеновской дифрактометрией $[11,15-19]$, однако ряд вопросов об объемной структуре гетероперехода остался нерешенным. В частности, остается открытым вопрос о деталях структуры этих пленок в плоскости, перпендикулярной электродам, что подчеркивалось в недавней работе [11]. Данный вопрос является важным для понимания работы современных высокоэффективных органических солнечных батарей, так как структура между электродами непосредственно влияет на транспорт заряда. Для изучения данного вопроса были приготовлены образцы с сечениями фотоактивных слоев вышеописанным методом, основанным на микротомировании. Для изучения структуры РТВ7: $\mathrm{PC}_{71} \mathrm{BM}$ в сечении (рис. $1, a$ ) использовались следующие методы зондовой микроскопии: измерение топографии в полуконтактном режиме и метод фазового контраста. Как отмечалось выше, применение атомно-силовой микроскопии для изучения сечения фотоактивного слоя и пространственной организации гетероперехода имеет ряд преимуществ по сравнению с другими методами, в частности электронной микроскопией, так как этот метод обеспечивает высокий контраст при достаточно высоком пространственном разрешении. Режим измерения фазы осциллирующего зонда позволяет определить распределение компонент в смеси, так как фаза зависит от различных свойств поверхности. Изменение фазы $\varphi$ при контакте осциллирующего зонда с поверхностью связано с потерями энергии: $\sin \varphi \propto E_{\mathrm{dis}}$, где $E_{\mathrm{dis}}-$ потери энергии зонда за период колебаний [25]. Таким образом, измеряемый фазовый контраст определяется свойствами поверхности, вызывающими потери энергии, такими как адгезия, трение, вязкоэластичность и др. В целом невозможно однозначно интерпретировать источник контраста на фазовом изображении ввиду сложности и многообразия причин, вызывающих сдвиг фазы. Однако данный метод является основным и общепринятым при исследовании 

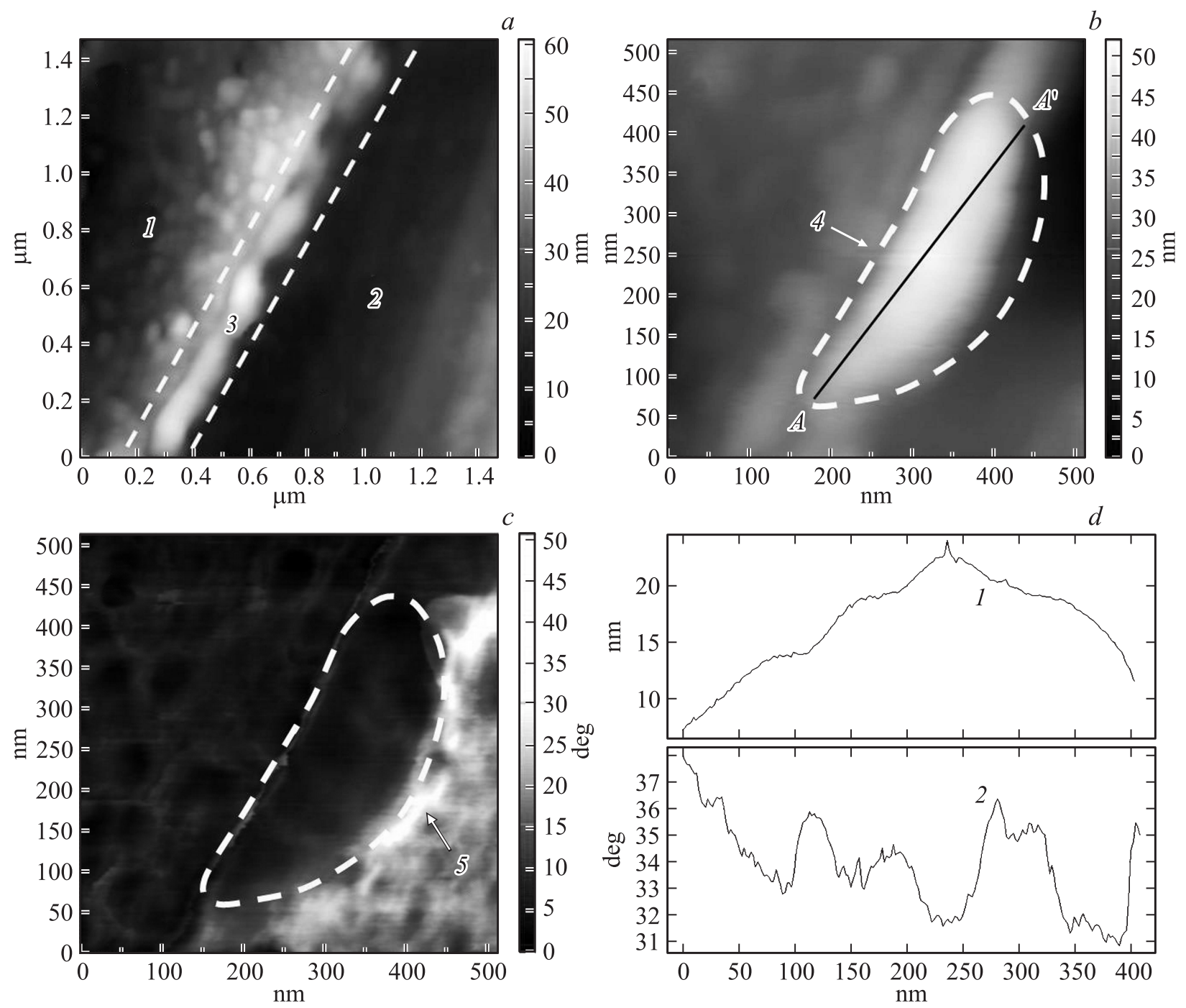

Рис. 2. Полученные методом АСМ изображения сечения пленки РТВ7: РС 71 ВМ: рельеф поверхности $(a, b)$ и фазовый контраст $(c)$; изображения $b$ и $c$ соответствуют одной и той же области. $1-$ ПЭТ, $2-\mathrm{CYTOР,} 3-$ слой РТВ7: РС 71 BM, $4-\mathrm{PEDOT,} 5-$ слой обогащенный PTB7. $d$ - рельеф (1), фаза колебаний зонда (2) в сечении $\mathrm{AA}^{\prime}($ см. $b)$.

полимерных образцов посредством сканирующих зондовых микроскопов и позволяет различать компоненты с различными свойствами в смесях с разрешением $\sim 1$ нм.

Результаты измерения структуры в сечении фотоактивного слоя для достаточно хорошо изученной смеси PTB7: PC $_{71}$ BM (без добавок) показаны на рис. 2, $a$, где хорошо виден фотоактивный слой (расположен между белыми штриховыми линиями). На рис. 2, $a, b, c$ видны домены, приблизительно эллиптической формы, которые были ранее исследованы методами просвечивающей электронной микроскопии [11]. С помощью метода сканирующей просвечивающей микроскопии с применением высокоуглового кольцевого темнопольного детектора (ВКТД-СПЭМ) нами также был измерен одиночный домен эллипсоидной формы на сечении пленки, полученной отрезанием тонкой ламели фокусированным ионным пучком (рис. 3). Внутри эллипсоидного домена на рис. 3 заметны неоднородности с нечеткими очерта- ниями, из чего невозможно сделать однозначный вывод о структуре внутри домена. Контраст на фазовом изображении (рис. 2,c) оказался гораздо более выраженным и позволяет определить внутреннюю структуру смеси. Хорошо просматривается структура внутри домена, которая говорит о том, что домен содержит и донор, и акцептор, распределенные неоднородно. Как было установлено ранее, домены преимущественно состоят из

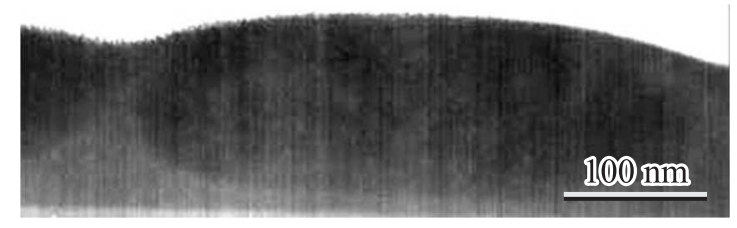

Рис. 3. ВКТД-СПЭМ-изображение эллипсоидного домена в сечении фотоактивного слоя РТВ7: $\mathrm{PC}_{71} \mathrm{BM}$. 
$\mathrm{PC}_{71} \mathrm{BM}[11,18,19]$, поэтому светлые прожилки в эллиптическом домене (рис. 2, $c$, справа) могут интерпретироваться как области, обогащенные полимером. В наших настройках режима измерений в полуконтактном режиме с доминированием сил отталкивания светлые области означают более мягкий материал, вызывающий бо́льшие потери энергии, т.е. полимер. На рис. 2, $d$ показаны рельеф и приведено фазовое изображение одной и той же области. Видно, что изменения фазы колебаний балки зонда происходят в местах с гладким рельефом, т.е. фазовый контраст отражает именно различный состав в домене. Отсутствие корреляции между рельефом и фазовым контрастом является одним из доказательств чувствительности измеренной фазы к составу поверхности. Таким образом, структура домена представляет собой области размером в несколько десятков нанометров, обогащенные фуллереном, разделенные областями со значительным содержанием полимера РТВ7. Распределение неоднородностей по толщине домена, их форма и размер в сечении пленки показаны впервые. Также на фазовом изображении (рис. 2,c) четко выделяется тонкий слой, обогащенный полимером, покрывающий эллипсоидный домен. Он выглядит как яркая область, примыкающая к пунктирной линии справа (обозначена 5).

Таким образом, применение комбинации микротомирования и измерения сечения образца методами зондовой микроскопии дает ценные сведения о наноструктуре фотоактивного слоя, что в общем подтверждается данными электронной микроскопии. Такой подход является комплементарным более распространенному методу измерения сечений с применением фокусированного ионного пучка и ПЭМ и позволяет использовать преимущества сканирующей зондовой микроскопии. Выявленные особенности строения домена позволяют, в частности, объяснить достаточно высокое значение эффективности преобразования энергии солнечных элементов на основе этой смеси $(6.2 \%$ [13]), а именно неоднородное строение домена повышает площадь объемного гетероперехода, что увеличивает количество экситонов, диссоциирующих с образованием свободных носителей заряда. Из рис. 2, с также следует возможность существования непрерывного пути для дырок в толще домена через прожилки полимера, что способствует транспорту заряда к электроду. В то же время наличие тонкой пленки, обогащенной полимером, покрывающей домены, может уменьшать эффективность солнечного элемента за счет ограниченного транспорта электронов к электроду.

Второй образец, исследованный нами, содержит сечение фотоактивного слоя PTB7:PC 71 BM:DIO. Для изучения структуры использовались следующие методы зондовой микроскопии: измерение топографии в полуконтактном режиме, метод фазового контраста, сканирующая микроскопия сил трения и метод ВКТД-СПЭМ. Обоснованием важности исследования данного образца является, в частности, предположение о разделении донора и акцептора в толще фотоактивного слоя, при котором концентрация полимера возрастает вблизи по-

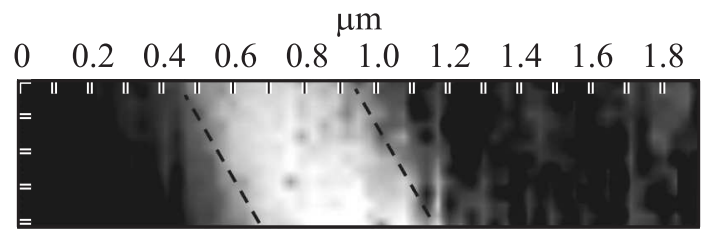

Рис. 4. Результаты измерения ГКР на сечении образца с пленкой PTB7: $\mathrm{PC}_{71} \mathrm{BM}$ :DIO. Штриховые линии - границы слоя РTB7: PC $_{71} \mathrm{BM}:$ DIO.

верхности центрифугированной смеси. Данное предположение основано на факте, что максимальная эффективность 9.2\% достигается при использовании инвертированной архитектуры [14]. Тогда обогащение поверхности полимером может активизировать транспорт заряда к электродам, так как полимер РТВ7 обладает дырочной проводимостью.

Для доказательства того, что приготовленный нами образец содержит сечение интересующей нас пленки, был проведен анализ химического состава поверхности среза с помощью микроскопии гигантского комбинационного рассеяния, усиленного зондом АСМ [26,27]. В работах $[23,24]$ было показано, что оптическое разрешение данного метода на полимерных образцах составляет 50-60 нм. Измеренный нами сигнал соответствует области спектра $1515-1570 \mathrm{~cm}^{-1}$, в которой находятся спектральные максимумы и полимера, и фуллерена. Результаты ГКР на сечении образца ясно выявили области, содержащие РТВ7 и $\mathrm{PC}_{71} \mathrm{BM}$, что подтверждает наличие фотоактивной пленки в приготовленном образце (рис. 4).

На рис. 5, а показана топография поверхности среза фотоактивного слоя PTB7: $\mathrm{PC}_{71} \mathrm{BM}: \mathrm{DIO}$, измеренная в полуконтактном режиме сканирующим зондовым микроскопом. Фотоактивный слой расположен между двумя штриховыми линиями. Некоторые вариации топографии на поверхности срезов могут быть объяснены в первую очередь дефектами ножа, а также неоднородными механическими свойствами срезаемой поверхности. Структура в виде полосок с периодом $\sim 150 \mathrm{Hм}$, расположенных перпендикулярно фотоактивному слою, является результатом вибраций при срезе. На рис. 5, $b, c$ показана топография поверхности среза и фазовый контраст для одной и той же области фотоактивного слоя PTB7:PC ${ }_{71} \mathrm{BM}:$ DIO.

Наиболее важным было определение степени однородности фотоактивного слоя в объеме PTB7: PC 71 BM:DIO. Из рис. 5, с следует, что свойства фотактивного слоя, вызывающие изменения фазы колебаний зонда АCM, однородны по толщине слоя. На фазовом контрасте видно только влияние топографии, никаких особенностей и включений в объеме пленки обнаружить не удалось. В случае изменения концентрации полимера фазовый контраст внутри фотоактивного слоя был бы неоднородным. Таким образом, результаты измерений методом АСМ показывают гомогенные свойства пленки 
$a$
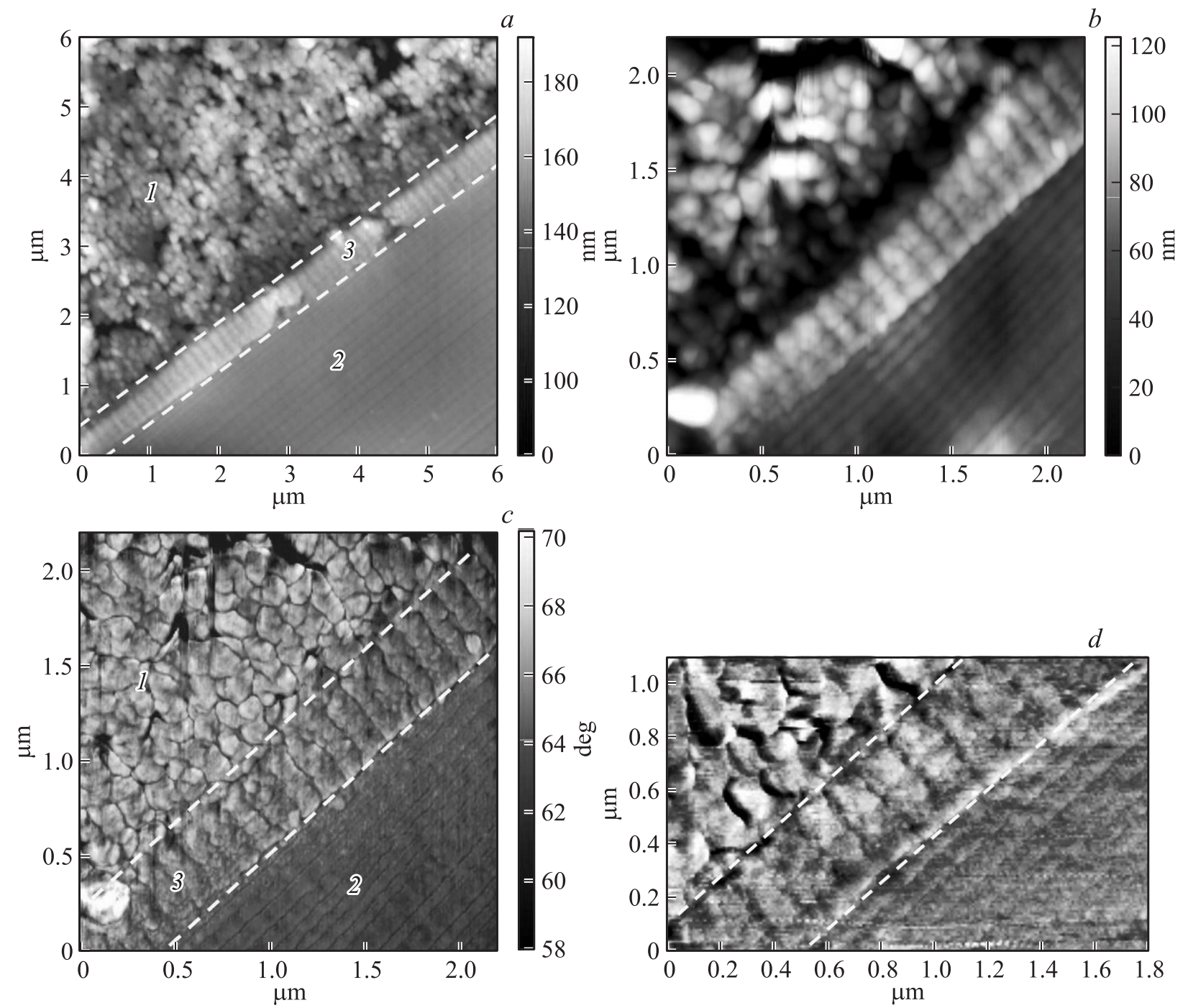

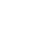

64

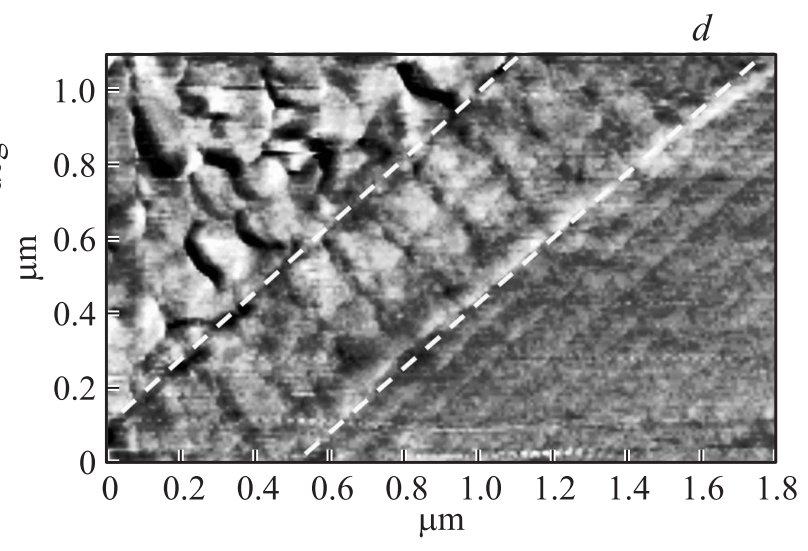

Рис. 5. Атомно-силовая микроскопия срезов $\mathrm{PTB} 7: \mathrm{PC}_{71} \mathrm{BM}: \mathrm{DIO}$ : топография $(a, b)$, фазовый контраст $(c)$ и распределение сил трения $(d)$. Изображения $b$ и $c$ получены для одной той же области. Фотоактивный слой расположен между штриховыми линиями. 1 - CYTOР, 2 - ПЭТ, 3 - слой РТВ7: $\mathrm{PC}_{71} \mathrm{BM}: \mathrm{DIO}$.

в объеме образца. Для подтверждения данного результата также применялась микроскопия сил трения, которая проводится в контактном режиме. При этом измеряются латеральные изгибы зонда, вызванные силами трения. Для контактных зондов, использованных в эксперименте, величина силы взаимодействия с поверхностью, оцененная по зависимости отклонения балки от координаты $Z$ сканера, была $<10$ нН. Такое низкое значение силы взаимодействия позволяет исследовать поверхность полимеров с минимальным разрушением в контактном режиме. На рис. $5, d$ показано распределение сил трения на сечении фотоактивного слоя PTB7: PC 71 BM:DIO. Из этих результатов снова следует, что распределение силы трения по толщине слоя однородно и, следовательно, донор и акцептор однородно перемешаны, по крайней мере с точностью до разрешения метода, т.е. нескольких нанометров. Контраст на рис. 5, $d$ повторяет черты, видимые на изображении поверхности (рис. $5, b$ ), нет никаких признаков разделения фаз и образования доменов. Рельеф поверхности оказывает влияние на фазу колебаний кантилевера и его боковые изгибы, однако наличие областей с разными свойствами проявлялось бы в виде контраста, не коррелирующего с рельефом.

Для подтверждения заключения о структуре пленки образец с сечением PTB7:PC ${ }_{71} \mathrm{BM}: \mathrm{DIO}$ исследовался с помощью ВКТД-СПЭМ. Результаты измерений и идентификация слоев в сечении образца приведены на рис. 6. Незначительные вариации контраста в фотоактивном слое не позволяют сделать вывод о наличии разделения фаз или образовании агломератов в пленке. Этот результат согласуется с выводами, сделанными на основании АСМ-измерений. Таким образом, результаты применения высокоразрешающих методов зондовой микроскопии и ВКТД-СПЭМ говорят о высокой степени перемешивания компонент в пленке PTB7: $\mathrm{PC}_{71} \mathrm{BM}$ :DIO и отсутствии заметных неоднородностей в толще плен- 


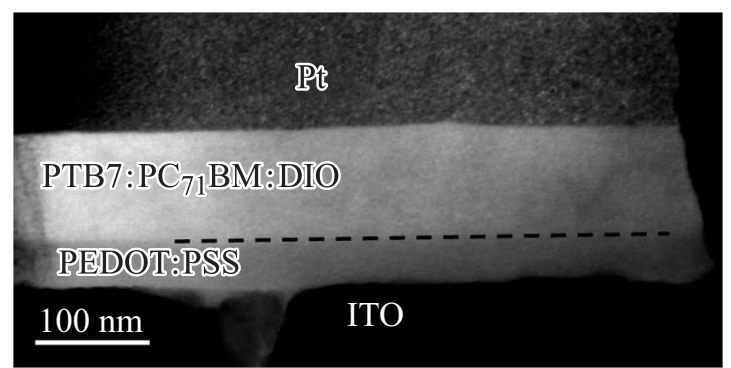

Рис. 6. ВКТД-СПЭМ-изображение сечения образца PTB7: $\mathrm{PC}_{71} \mathrm{BM}: \mathrm{DIO}$.

ки на нанометровой шкале. Этот вывод важен для понимания работы батарей на основе РТВ7: $\mathrm{PC}_{71} \mathrm{BM}$ с добавкой $3 \%$ DIO, которые показали рекордную до недавнего времени эффективность преобразования энергии однослойных ПСЭ в $9.2 \%$.

Таким образом, ранее сделанное предположение о разделении полимера и фуллерена в объеме фотоактивного слоя РTB7: $\mathrm{PC}_{71} \mathrm{BM}: \mathrm{DIO}$, при котором происходит обогащение поверхности полимером, не подтверждается нашими результатами. Тот факт, что именно инвертированная конфигурация солнечной ячейки привела к максимальной эффективности для рассмотренных донора и акцептора, требует дополнительных объяснений и исследований. Дальнейшее развитие данного метода исследований требует усовершенствования режимов микротомирования для получения более качественных срезов. В частности, представляется перспективным ультрамикротомирование при охлаждении образца жидким азотом.

\section{4. Заключение}

В данной работе описан и применен метод изучения внутренней структуры органических солнечных элементов на основе микротомирования и использования методов зондовой микроскопии. Примененный подход позволил выявить детали строения обогащенных фуллереном доменов в фотоактивном слое РТВ7: $\mathrm{PC}_{71} \mathrm{BM}$. Сравнение полученных результатов с данными ПЭМ позволяет сделать вывод о перспективности данного подхода для выявления деталей структуры и определения локальных свойств смесей органических материалов в объеме с нанометровым разрешением. Полученные различными методами зондовой микроскопии результаты для смеси PTB7 : PC 71 BM:DIO позволили сделать вывод о высокой степени перемешивания компонент в объеме смеси и отсутствии фазовой сегрегации на нанометровой шкале.

Работа выполнена при поддержке МОН Республики Казахстан (4360/GF4, программа НУ-Беркли 0115РК03029) и Министерства образования и науки РФ, ГК № 14.578.21.0188 (Уникальный идентификатор соглашения RFMEFI57816X0188). Исследование
C.С. Харинцевым выполнено при поддержке Российского фонда фундаментальных исследований № 15-4202339. А. Ал-Афееф благодарен фонду Лорда Кельвина/Адама Смита за финансовую поддержку.

Авторы благодарны Д.А. МакЛарену и И. МакЛарену (Университет Глазго) за помощь в получении ВКТД-СПЭМ-изображений.

Часть работ выполнялась на оборудовании ЦКП „МСТ и ЭКБ“.

\section{Список литературы}

[1] W. Zhao, D. Qian, S. Zhang, S. Li, O. Inganäs, F. Gao, J. Hou. Adv. Mater., 28, 4734 (2016).

[2] S. Zhang, L. Ye, J. Hou. Adv. Energy Mater., 6, P1502529 (2016).

[3] Q. Wan, X. Guo, Z. Wang, W. Li, B. Guo, W. Ma, M. Zhang, Y. Li. Adv. Funct. Mater., 26, 6635 (2016).

[4] C.J. Brabec, N.S. Saricifci, J.C. Hummelen. Adv. Funct. Mater., 11, 15 (2001).

[5] X. Yang, J. Loos, S.C. Veenstra, W.J.H. Verhees, M.M. Wienk, J.M. Kroon, M.A.J. Michels, R.A.J. Janssen. Nano Lett., 5, 579 (2005).

[6] S.D. Oosterhout, M.M. Wienk, S.S. van Bavel, R. Thiedmann, L.J.A. Koster, J. Gilot, J. Loos, V. Schmidt, R.A.J. Janssen. Nature Materials, 8, 818 (2009).

[7] M.J.M. Wirix, P.H.H. Bomans, M.M.R.M. Hendrix, H. Friedrich, N.A.J.M. Sommerdijk, G. de With. J. Mater. Chem. A, 3, 5031 (2015).

[8] A. Alexeev, J. Loos, M.M. Koetse. Ultramicroscopy, 106, 191 (2006).

[9] D.C. Coffey, O.G. Reid, D.B. Rodovsky, G.P. Bartholomew, D.S. Ginger. Nano Lett., 7, 738 (2007).

[10] J. Loos, J.K.J. van Duren, F. Morrissey, R.A.J. Janssen. Polymer, 43, 7493 (2002).

[11] A. Alekseev, G.J. Hedley, A. Al-Afeef, O.A. Ageev, I.D.W. Samuel. J. Mater. Chem. A, 3, 8706 (2015).

[12] M. Scherer, R. Saive, D. Daume, M. Kröger, W. Kowalsky. AIP Advances, 3, 092134 (2013).

[13] Y. Liang, Z. Xu, J. Xia, S.T. Tsai, Y. Wu, G. Li, C. Ray, L. Yu. Adv. Mater., 22, E135 (2010).

[14] Z. He, C. Zhong, S. Su, M. Xu, H. Wu, Y. Cao. Nature Photonics, 6, 591 (2012).

[15] S.J. Lou, J.M. Szarko, T. Xu, L. Yu, T.J. Marks, L.X. Chen. J. Am. Chem. Soc., 133, 20661 (2011).

[16] M.R. Hammond, R.J. Kline, A.A. Herzing, L.J. Richter, D.S. Germack, H.-W. Ro, C.L. Soles, D.A. Fischer, T. Xu, L. Yu, M.F. Toney, D.M. DeLongchamp. ACS Nano, 5, 8248 (2011).

[17] B.A. Collins, Z. Li, J.R. Tumbleston, E. Gann, C.R. McNeill, H. Ade. Adv. Energy Mater., 3, 65 (2012).

[18] F. Liu, W. Zhao, J.R. Tumbleston, C. Wang, Y. Gu, D. Wang, A.L. Briseno, H. Ade, T.P. Russell. Adv. Energy Mater., 4, 1676 (2014).

[19] G.J. Hedley, A.J. Ward, A. Alekseev, C.T. Howells, E.R. Martins, L.A. Serrano, G. Cooke, A. Ruseckas, I.D.W. Samuel. Nat. Commun., 4, 2867 (2013).

[20] J. Loos, E. Sourty, K. Lu, G. de With, S. van Bavel. Macromolecules, 42, 7 (2009). 
[21] E. Sourty, S. van Bavel, K. Lu, R. Guerra, G. Bar, J. Loos, Microsc. Microanal., 15, 251 (2009).

[22] Z. He, B. Xiao, F. Liu, H. Wu, Y. Yang, S. Xiao, C. Wang, T.P. Russell, Y. Cao. Nature Photonics, 9, 174 (2015).

[23] S. Kharintsev, A. Alekseev, V. Vasilchenko, A. Kharitonov, M. Salakhov. Optical Mater. Express, 5 (10), 2225 (2015).

[24] S. Kharintsev, A. Alekseev, J. Loos. Spectrochim. Acta A, 171, 139 (2017)

[25] J.P. Cleveland, B. Anczykowski, A.E. Schmid, V.B. Elings. Appl. Phys. Lett., 72, 2613 (1998).

[26] L. Novotny, B. Hecht. Principles of Nano-Optics (N.Y., Cambridge University Press, 2012).

[27] P. Verma, T. Ichimura, T. Yano, Y. Saito, S. Kawata. Laser Photonics Rev., 4, 548 (2010).

Редактор Л.В. Шаронова

\section{Study of the structure of bulk heterojunction in oganic solar cells by combination of ultramicrotomy and atomic force microscopy}

A.M. Alekseev ${ }^{1,2}$, A. Al-Afeef ${ }^{3}$, G.J. Hedley ${ }^{4}$, S.S. Kharintsev ${ }^{5}$, A.E. Efimov ${ }^{6}$, A.T. Yedrisov ${ }^{1}$, N.A. Dyuzhev ${ }^{2}$, I.D.W. Samuel ${ }^{4}$

${ }^{1}$ National Laboratory Astana, Nazarbayev University, 010000 Astana, Kazakhstan

${ }^{2}$ National Research University of Electronic Technology, 124498 Moscow, Russia

${ }^{3}$ School of Physics and Astronomy, University of Glasgow, G128QQ Glasgow, United Kingdom ${ }^{4}$ School of Physics and Astronomy, University of St. Andrews, KY16 9AJ Fife, Scotland, United Kingdom

${ }^{5}$ Institute of Physics, Kazan Federal University, 420111 Kazan, Russia ${ }^{6}$ Shumakov Federal Research Center for Transplantology and Artificial Organs, 123182 Moscow, Russia

Abstract The method of visualization of an internal structure of photoactive layers in polymer solar cells by using atomic force microscopy and microtome is described and applied in this work. This method enables to use advantages of atomic force microscopy methods for study structure of soft materials in bulk, such as high contrast imaging and possibility to determine local properties with nanometer resolution. The described method is used for investigation of the photoactive layers of polymer solar cells, which contain mixture of polythiophene derivative PTB7 and fullerene derivative $\mathrm{PC}_{71} \mathrm{BM}$. New details of bulk structure of this blend were discovered. The obtained results help to understand better influence of morphology on performance of polymer solar cells. 